\title{
On Explanation of Polygons in Galilean Geometry to High School Students
}

\author{
Abdullah Kurudirek, Huseyin Akca \\ Tashkent State Pedagogical University, Tashkent, Uzbekistan \\ Email: drcebir@hotmail.com, huseyinakcha@gmail.com \\ Received 1 June 2015; accepted 19 June 2015; published 24 June 2015 \\ Copyright (C) 2015 by authors and OALib. \\ This work is licensed under the Creative Commons Attribution International License (CC BY). \\ http://creativecommons.org/licenses/by/4.0/ \\ (c) (i) Open Access
}

\begin{abstract}
In this paper, we have tried to indicate the own properties of polygons in Galilean geometry using the Affine concepts as well. The relationships between an angle and a side as well as the relationships between altitudes and medians concepts, and comparison of some special polygons have been examined carefully. In addition, the area concept has been mentioned. Finally, the paper was completed with a new idea, Theorem 6.
\end{abstract}

\section{Keywords}

Galilean Plane, Kinematic, Projection, Special Line, Support Line

Subject Areas: Geometry, Geometry Education

\section{Introduction}

Düzlemde, Galileo geometrisi Öklid geometrisinden vektör normu (uzunluğu) veya noktalar arasındaki mesafenin tanımlanış biçiminden dolayı ayrılır [1]. Bundan dolayı da Galileo geometrisindeki doğru, doğru parçası, doğruların paralelliği gibi Afin kavramlar Öklid geometrisinden farklı değildir. Bu birliktelik bize Galileo geometrisinde çokgenlerin de aynı Öklid geometrisindeki gibi tanımlanma imkanını vermektedir.

Galileo geometrisinde mesafenin tanımlanması, herhangi bir şekildeki çokgeni öğrenme imkanı vermemektedir. Bundan dolayı, Galileo düzleminde öğrenilen çokgenlerin hiç bir kenarının özel doğrular üzerinde bulunmadığını baştan kabul edelim. Dolayısıyla da çokgenlerin ardarda gelen köşeleri özel bir doğru üzerinde olamayacağı sonucu ortaya çıkmış olacaktır [2].

Galileo düzlemindeki üçgen ve ona ait elemanların özellikleri yeterli seviyede anlatılmış ve öğrenilmiş bulunmaktadır. Biz bunlardan en önemlisini (Şekil 1) alıp üzerinde çalışalım istedik. Şimdi Galileo düzleminde, kenarlarını $a, b, c$ ve iç açılarıda $\hat{A}, \hat{B}, \hat{C}$ ile gösterilen bir $A B C$ üçgeni verilmişolsun. 


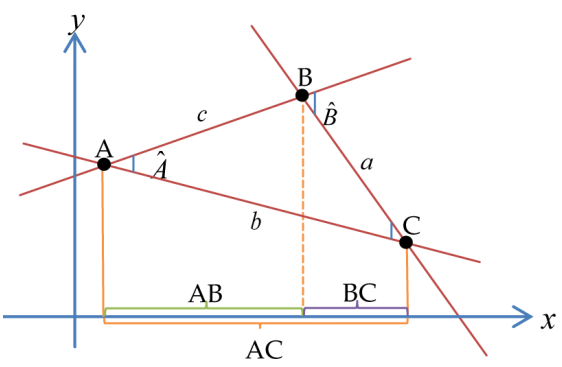

Şekil 1. Galileo düzleminde üçgen.

Burada üçgenin kenarları ve açıları arasında $a+c=b$ ve $\hat{A}+\hat{C}=\hat{B}$ eşitlikleri sağlanmaktadır. Kenarlar arasındaki ilişki sayesinde, Galileo geometrisinde eşkenar üçgenin olmadığını hemde açılardan dolayı üç açınında eş açılı bir üçgen oluşturamayacağını bizlere göstermektedir. Ama ikizkenar üçgenimiz mevcut ve onun tabanındaki açılarında birbirine denk olduğunu yine kolay bir ödev olarak öğrencilerimize bırakabiliriz.

Üçgendeki kenarortay kavramı da yine aslında Afin kavramı olduğu için Öklid geometrisindeki özellikleri Galileo geometrisinde de geçerlidir. Yani üçgenin kenarortayı üçgenin kenarlarıyla bir noktada kesişir ve $\frac{1}{2}$ oranında böler. Galileo geometrisindeki açı, Öklid geometrisindeki açı düşüncesinden tamamen farklıdır. Bu durum bize üçgendeki açıortayın Galileo geometrisinde yeni bir kavram olduğunu gösterir. Demek, Galileo geometrisindeki açırtay Öklid geometrisindeki üçgenin açıortayından ayrılmaktadır. Üçgenin yüksekliği ise Galileo geometrisinde kendisine ait özellikler göstermektedir.

\section{Tanim}

Galileo geometrisinde bir üçgenin yüksekliği diye üçgenin köşesinden çizilen özel doğrunun karşı kenar ile kesişmesinden oluşan özel doğru parçasına denir. Bu tanımda, Öklid geometrisindeki üçgenin yüksekliğinin noktadan doğruya kadar olan en kısa mesafe olması özelliği korunmaktadır. Ama yüksekliğin karşı kenara dik olması durumu şart değildir. Öklid geometrisindeki üçgen eşitliği şartlarından birinci ve ikincisi Galileo geometrisinde de geçerlidir. Bu durumları aşă̆ıdaki Teoremlerle hatırlayabiliriz.

\section{Teorem 1.}

Eğer bir üçgenin iki kenarı ve onlar arasındaki açıyla, ikinci üçgenin iki kenarı ve onlar arasındaki açı karşılıklı eşit olursa bu üçgenler kendi aralarında eşittirler.
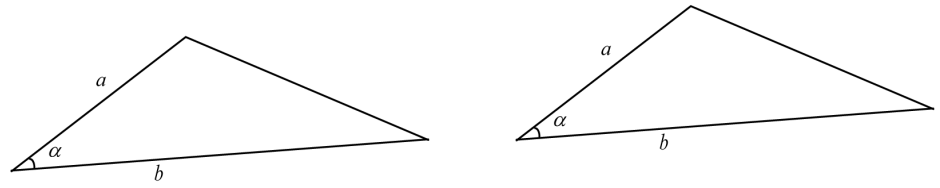

\section{Şekil 2. Eşit Üçgenler.}

Teorem 2.

Eğer bir üçgenin kenarı ve ona komşu iki açıyla, ikinci üçgenin bir kenarı ve ona komşu açıları karşılıklı eşit olursa bu üçgenler kendi aralarında eşittirler.
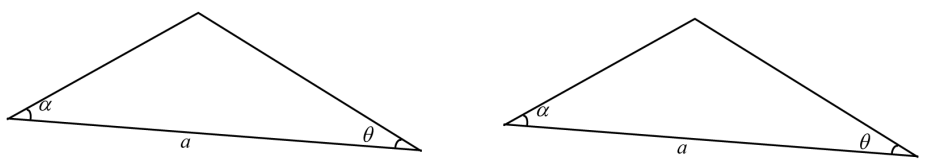

Şekil 3. Eşit Üçgenler.

Bu Teoremlerin ispatı zor olmamakla beraber, yaygın bir şekilde okullarda geometri derslerinde öğretilmektedir. Esasen bu ispatlar Galileo geometrisindeki hareket konusunun özelliklerini öğrenme imkanı vermektedir. 
Üçgenlerin kenarları arasında eşitlik şartı Galileo geometrisinde geçerli değildir. Kenarları ve açıları karşılıklı eşit olan üçgenlerin eşit olma şartı yoktur [2]. Bu durum aşağıda 4. ve 5. şekillerde açıkca görülmektedir.

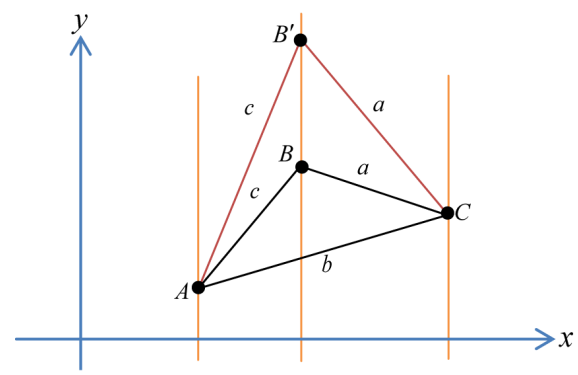

Şekil 4. Üçgenlerin kenar ilişkisi.

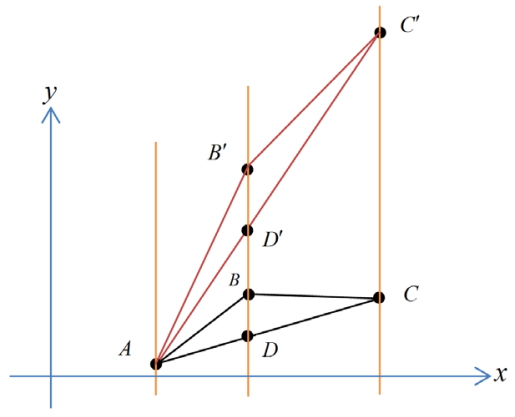

Şekil 5. Üçgenlerin kenar ilişkisi.

Şimdi Galileo geometrisinde sade bir dörtgen olan paralelkenar ile tanışalım. Paralelkenarın karşlıklı kenarları ve karşılıklı açıları birbirine eşittir. Bu özelliğin Öklid geometrisinde de geçerli olduğu hemde mesafenin Öklid mesafesinin izdüşümü kavramı olduğu sonucu ortaya çıkar.

Teorem 3.

Karşılıklı köşeleri özel bir doğru üzerinde bulunan paralelkenar, Şekil 6 da gösterildiği gibi, eşkenar dörtgendir. Eşkenar dörtgenin köşegenleri birbirlerini ortalar.

Gerçekten de paralelkenarın eşkenar dörtgen olması için, onun bütün kenarlarının birbirine eşit olması gerekmektedir. Çokgenin bir köşesinden çizilen iki kenarın denk olması için onların ikinci köşelerinin bir özel doğru üzerinde olması zaruri ve yeterli sebeptir. Buradan paralelkenarın köşegenlerinden birinin özel doğru üzerinde bulunması fikri ortaya çıkar. İkinci köşegeni ise özel doğru üzerinde bulunmaz. Özel doğru, özel olmayana diktir buda teoremin geçerli olduğunu gösterir.

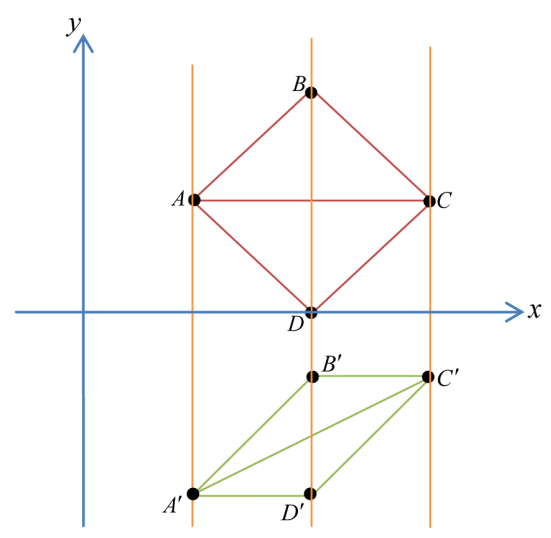

Şekil 6. Eşkenar dörtgen \& Paralelkenar. 
Ne yazık ki, Galileo geometrisinde dikdörtgen ve kare düşünceleri genelleştirilememektedir. Galileo geometrisinde her hangi $n$-dışbükey çokgeninin iki özel doğrudan oluşan dayanak doğruları ve $(n-2)$ tane kenarları özel doğrulara oranla her çeşit yarım düzlemde yerleşmiş köşeleri vardır. Bunlar sırasıyla dayanak köşe ve dayanak doğruları diye adlandırılır.

\section{Teorem 4.}

Galileo geometrisinde çokgenin (Şekil 7) dayanak köşeleri açılarının ölçüleri toplamı diğer köşelerin açı ölçülerinin toplamına eşittir.

Eğer dayanak köşeleri açılarının ölçüleri $\alpha$ ve $\beta$ ile ve diğer köşelerin açı ölçülerini $\theta_{i}$ ile gösterecek olursak, $\alpha+\beta=\sum_{i=1}^{n-2} \theta_{i} \quad(i=1,2, \cdots, n-2)$ olur.

$\mathrm{Bu}$ teoremi çokgenin dayanak köşelerinin birinden çizilen köşegenler yardımında $n-2$ tane üçgene ayırıp oluşan üçgenlerin açılarından faydalanabiliriz.

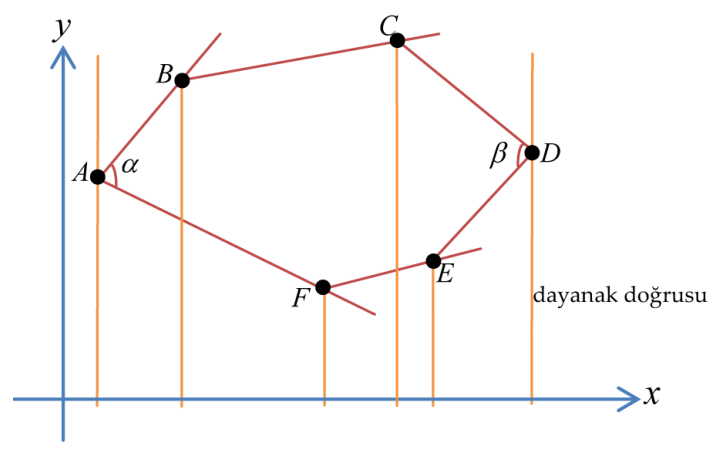

\section{Şekil 7. Çokgen.}

Meydana gelen $n-2$ tane eşitliği karşılıklı topladığımızda teoremin ispatını da tamamlamış oluruz. Eğer dış açı işaretinin eksi olarak tanımlanmasından faydalanacak olursak; Galileo geometrisinde çokgenin iç açıları toplamının sıfıra denk olduğu görülecektir. Bunu kolaylıkla bir üçgen üzerinde Şekil 8 de olduğu gibi, $\alpha+\theta=\beta$ hatırlayarak aşağıda ki gibi ispat edebiliriz [3].

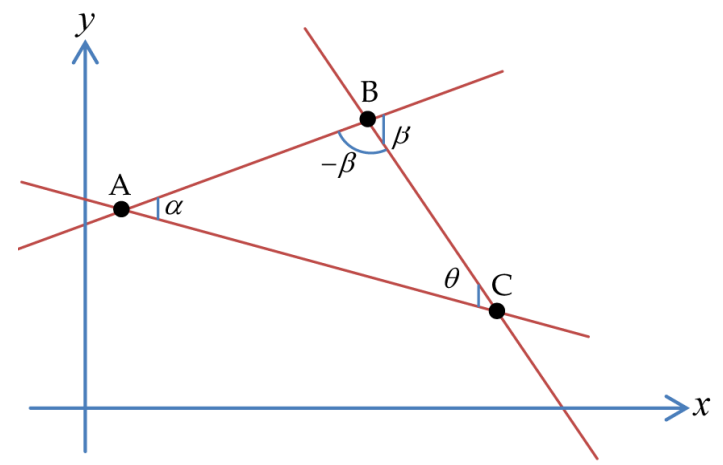

Şekil 8. İç açılar toplamı.

$\alpha+(-\beta)+\theta=0$.

Geometride alan ve hacim düşüncelerine de yine Afin kavramları olarak bakabiliriz. Dolayısıyla Galileo geometrisindeki alan Öklid geometrisindeki alan ile aynı olacaktır [4].

Teorem 5.

Bir üçgenin alanı, onun tabanıyla yüksekliğinin çarpımının yarısına eşittir.

İspat: Tabanı $A C$ olan ve $o x$ - koordinat ekseninde yerleştirilmiş $A B C$ üçgenine bakalım. Burada üçgenin Öklid manasındaki alanı $S_{A B C}=\frac{1}{2} A C \cdot B D$ dir. 


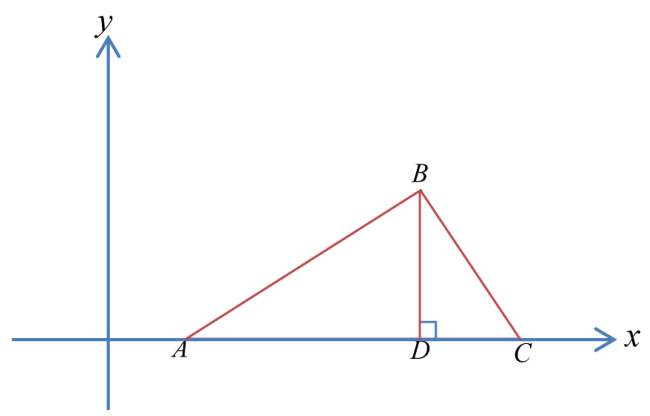

Şekil 9. Üçgen.

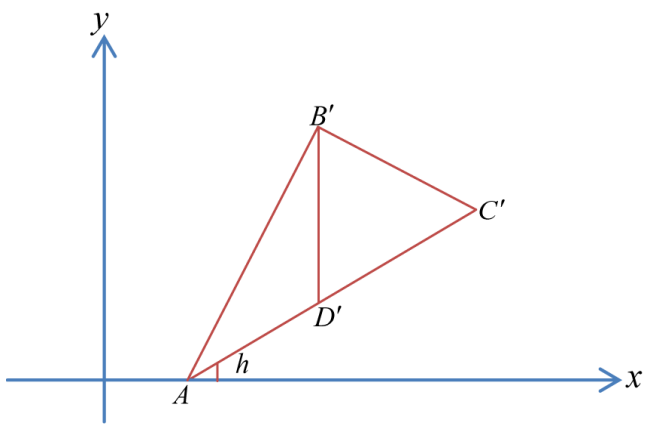

\section{Şekil 10. Üçgen.}

$A B C$ üçgenimizi $A$ köşesinden $h$ açısı kadar döndürdükten sonra,

$S_{B^{\prime} D^{\prime} C^{\prime}}=S_{B D C}$ ve $S_{B^{\prime} D^{\prime} A}=S_{A B D}$ olur. Bunlardan da $S_{A B^{\prime} C^{\prime}}=S_{A B^{\prime} D^{\prime}}+S_{B^{\prime} D^{\prime} C^{\prime}}$ elde edilir. Fakat $A C$ kenar1 $A B C$ üçgeninin tabanı ve $B D$ doğru parçası özel doğru üzerinde bulunmaktadır. Dolayısıyla Galileo geometrisinde de $A C$ taban ve $B D$ de yüksekliktir. Alanlar eşitliğinden teoremin doğru olduğu ortaya çıkacaktır.

Şekil 10 da gösterildiği gibi Galileo geometrisindeki hareket esnasında taban uzunluğu ve yüksekliği değişmemektedir [5]. Dolayısıyla eşitliğin herhangi bir üçgen için geçerli olduğu ortaya çıkacaktır. Şimdi bir üçgenin $A, B, C$ köşelerinden geçen yükseklikleri sırasıyla $h_{a}, h_{b}, h_{c}$ ile gösterelim ve Galileo geometrisinde açı ve yükseklik tanımlarından da faydalanarak Şekil 11' i oluşturalım.

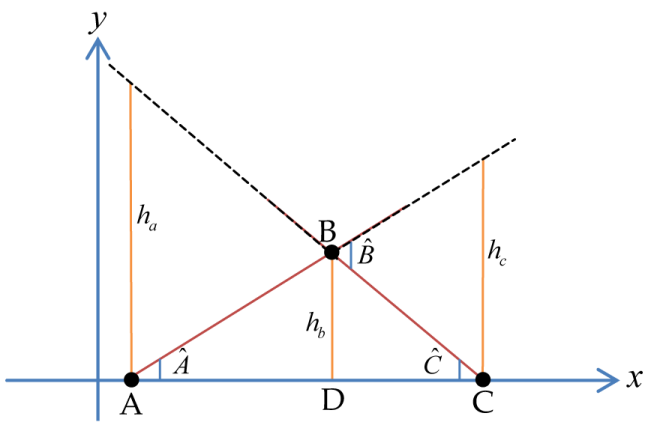

Şekil 11. Galileo geometrisinde üçgenin açı ve yükseklikleri.

$\frac{h_{b}}{h_{a}}=\frac{D C}{A C} \Rightarrow h_{b} \cdot A C=h_{a} \cdot D C$ ve $\frac{h_{c}}{h_{b}}=\frac{A C}{A D} \Rightarrow h_{b} \cdot A C=h_{c} \cdot A D$ eşitliklerini, ve buradan da,

$S=\frac{1}{2} h_{b} \cdot A C=\frac{1}{2} h_{a} \cdot D C=\frac{1}{2} h_{a} \cdot B C$ ve $S=\frac{1}{2} h_{b} \cdot A C=\frac{1}{2} h_{c} \cdot A D=\frac{1}{2} h_{c} \cdot A B$ eşitliklerini yazabiliriz. 
Şekil 12 de gösterildiği gibi, Galileo geometrisinde bir üçgenin alanı iki kenar uzunluğu ve arasında kalan açının çarpımının yarısına eşit olduğu görülür. Alanı ifade eden eşitliklerden faydalanarak;

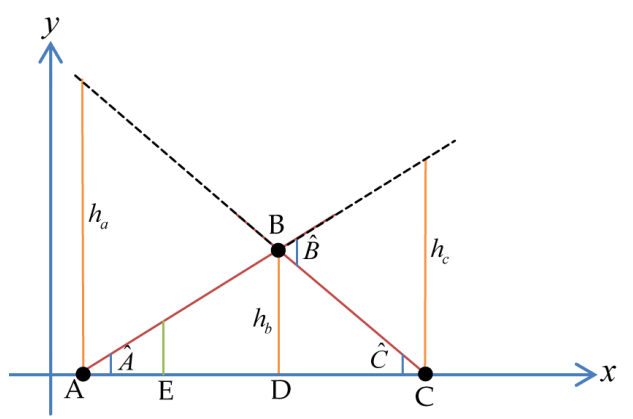

\section{Şekil 12. Üçgen.}

1. durum: $\frac{h_{a}}{\hat{C}}=\frac{A C}{A E} \Rightarrow \frac{h_{a}}{\hat{C}}=\frac{A C}{1}$ buradan $h_{c}=A C \cdot \hat{C} \quad$ ve $S=\frac{1}{2} B C \cdot h_{a}=\frac{1}{2} B C \cdot A C \cdot \hat{C} \quad$ olur.

2. durum: $\frac{h_{b}}{\hat{A}}=\frac{A D}{A E} \Rightarrow \frac{h_{b}}{\hat{A}}=\frac{A D}{1}$ buradan $h_{b}=A D \cdot \hat{A}=A B \cdot \hat{A}$ ve $S=\frac{1}{2} A C \cdot h_{b}=\frac{1}{2} A C \cdot A B \cdot \hat{A}$ olur.

3. durum: $\frac{h_{c}}{\hat{B}}=\frac{B C}{A E} \Rightarrow \frac{h_{c}}{\hat{B}}=\frac{B C}{1}$ buradan $h_{c}=B C \cdot \hat{B} \quad$ ve $S=\frac{1}{2} A B \cdot h_{c}=\frac{1}{2} A B \cdot B C \cdot \hat{B}$ olur.

Bu üç durumdan; $S=\frac{1}{2} A C \cdot A B \cdot \hat{A}=\frac{1}{2} A B \cdot B C \cdot \hat{B}=\frac{1}{2} B C \cdot A C \cdot \hat{C} \quad$ eşitliği yazılabilinir. Daha sonra bu eşitlik $\frac{1}{2} A B \cdot B C \cdot A C$ ile sadeleştirildikten sonra $\frac{\hat{A}}{B C}=\frac{\hat{B}}{A C}=\frac{\hat{C}}{A B}$ eşitliğini elde edebiliriz. Bu eşitlik Öklid geometrisindeki Sinüs teoreminin benzeri olduğu görülür.

Galileo düzleminde herhangi bir $A\left(x_{0}, y_{0}\right)$ noktası alalım. Şekil 13 de gösterildiği gibi köşegeni $O A$ olan, kenarları bir birimlik mesafedeki özel doğru parçalarından oluşan $O B A C$ paralelkenarını çizelim. Burada $B(0,1)$ ve $C\left(x_{0}, y_{0}-1\right)$ koordinatların belirtelim.

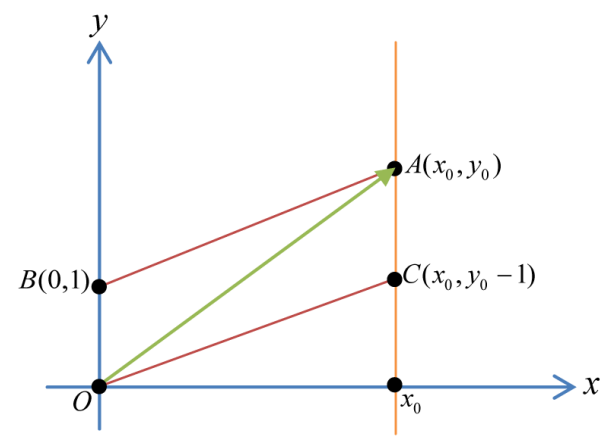

Şekil 13. Bir köşesi orjinde bulunan paralelkenar.

$S_{\text {OBAC }}=O B \cdot O C=1 \cdot x_{0}=x_{0}$ ve $|\boldsymbol{O A}|=x_{0}$ buradan da $S_{\text {OBAC }}=|\boldsymbol{O A}|$ olur.

\section{Sonuç}

Sonuç olarak Galileo geometrisini, vektör normuna ait dörtgenin alanına eşit olan vektör uzayı şeklinde de öğrenebilmemiz mümkündür. İşte bu sonuçtan aşağıdaki Teoremi yazabiliriz.

Teorem 6.

Köşeleri $O B A C$ noktalarında olan dörtgenin alanı $O A$ vektörünün normuna (uzunluğuna) eşittir. 


\section{References}

[1] Yaglom, I.M. (1979) A Simple Non-Euclidean Geometry and Its Physical Basis. Springer-Verlag, New York.

[2] Kurudirek, A. and Akca, H. (2015) Explanation of Distance, Kinematic and Isometry to High School Students from Different Perspective. Macrothink Institute, International Research in Education, 3.

[3] Kurudirek, A. and Akça, H. (2015) On the Concept of Circle and Angle in Galilean Plane. Open Access Library Journal, 2, e1256. http://dx.doi.org/10.4236/oalib.1101256

[4] Artıkbayev, A., Kurudirek, A. and Akça, H. (2013) Occurrence of Galilean Geometry. Applied and Computational Mathematics, 2, 115-117. http://dx.doi.org/10.11648/j.acm.20130205.11

[5] Kurudirek, A., Akça, H. and Erdoğan, M. (2013) On Geometries in Affine Plane. Applied and Computational Mathematics, 2, 127-129. http://dx.doi.org/10.11648/j.acm.20130206.13 